\title{
Improving Referrals for HIV Care Through Organizational Network Analysis
}

\author{
James C. Thomas, PhD, MPH; Bernard Agala, PhD; Khou Xiong, MPH; Richard Powell, MA, MSc
}

\begin{abstract}
Context: The link between testing for HIV and obtaining antiretroviral therapy (ART) is central to the HIV/AIDS control strategies of UNAIDS (the "90-90-90" goals) and the International Association of Providers of AIDS Care ("Test and Start"). To ensure that $90 \%$ of those diagnosed with HIV/AIDS begin ART and $90 \%$ of those on ART achieve viral suppression, service providers not providing all services need to refer patients to other organizations.

Setting: Homa Bay, Kenya.

Objective: Homa Bay county's HIV/AIDS prevalence is one of the country's highest. We identified the organizations providing some aspect of HIVIAIDS care and investigated ways in which they work together, or do not, to cover the comprehensive needs of those they serve.

Design and Participants: We identified 56 organizations and interviewed a representative from each about his or her organization's services and its connections with the other 55, with particular interest in referrals from sites that test for HIV but do not treat infections to sites that do treat infections.

Main Outcome Measure: Referral connections.

Results: Referral connections among the 56 in the past 30 days were relatively rare, averaging fewer than 2; 13 organizations made no referrals at all. Notably, 5 facilities that test for HIV did not refer their clients to an ART provider. We found 2 distinct clusters of connected organizations: one in Homa Bay Township and the other in Rangwe subcounty. When we convened the organizations and presented our results to them, they expressed interest in establishing better connections and referrals.

Conclusions: Homa Bay has an opportunity to improve care for people with HIV/AIDS, in particular ensuring that those testing positive receive treatment, simply by making better use of the services already available. This can be achieved by informing each organization of the services provided by each of the others and by bringing the organizations together to plan and monitor the services' coordination. These steps could be implemented separately in each of the 2 organizational clusters.
\end{abstract}

\section{KEY WORDS: antiretroviral therapy, less-developed countries, local area networks, referral}

\section{Author Affiliations: MEASURE Evaluation, Carolina Population Center (Drs Thomas and Agala and Ms Xiong), and Department of Epidemiology, Gillings School of Global Public Health (Dr Thomas), University of North Carolina, Chapel Hill, North Carolina; and MEASURE Evaluation PIMA Project, Nairobi, Kenya (Mr Powell). \\ For their assistance with the study, the authors thank the study participants in Homa Bay; Vincent Waringa, the Homa Bay County Deputy Director of Health; the staff of the MEASURE Evaluation PIMA Project in Kenya; and the MEASURE Evaluation project staff in Chapel Hill, North Carolina. MEASURE Evaluation is funded by the US Agency for International Development (USAID) under cooperative agreement AID-OAA-L-14-00004 and is implemented by the Carolina Population Center at the University of North Carolina at Chapel Hill, in association with ICF International; John Snow, Inc; Management Sciences for Health; Palladium; and Tulane University. \\ The opinions expressed in this publication do not necessarily reflect the views of USAID or the US government. \\ The authors declare no conflicts of interest.}

Correspondence: James $C$. Thomas, PhD, MPH, Department of Epidemiology, Gillings School of Global Public Health, University of North Carolina, CB \#7435, Chapel Hill, NC 27599 (jim.thomas@unc.edu). n 2014, the Joint United Nations Program on HIV/AIDS (UNAIDS) announced its 90-90-90 goals for HIV/AIDS: by the year 2020, $90 \%$ of all people living with HIV should have been diagnosed, $90 \%$ of those diagnosed should be on HIV/AIDS treatment, and $90 \%$ of those treated should have viral suppression. ${ }^{1}$ Similarly, "Test and Start" is the standard practice recommended by the International Association of Providers of AIDS Care. ${ }^{2}$ People living with HIV have many health and social needs that affect their ability to follow this cascade of goals. A wide array of services address those needs, but very few organizations provide the full array. More commonly, an infected person needs services from several organizations providing antiretroviral therapy (ART) and supportive care. ${ }^{3}$ To facilitate referrals and ideally follow-up to ensure that their patients receive all needed services, those organizations need to facilitate referrals. 
Improving health outcomes through coordination and integration of health interventions within a strong and well-functioning health system is an essential principle of the Global Health Initiative. ${ }^{4}$ Interprovider care coordination has been shown to improve HIV-positive clients' health outcomes. ${ }^{5}$ Thomas and colleagues ${ }^{6}$ also reported that HIV-positive clients are more satisfied $\mathrm{w}$ ith s ervices $\mathrm{i} \mathrm{n}$ acility networks where interaction and coordination are high. Together, these findings s uggest $t$ hat strengthening HIV-positive client referrals among facilities can improve treatment access and ultimately help achieve the UNAIDS 90-90-90 goals.

Populations bordering Lake Victoria are among those most in need of achieving the 90-90-90 goals in East Africa. Homa Bay County, Kenya, has the highest HIV/AIDS prevalence in the country, estimated at more than $26 \%$, with more than 130000 adults and 23000 children living with the virus. ${ }^{8}$ Despite the substantial benefits of ART in reducing mortality and onward HIV transmission and disease burden, 44\% of 54000 adults and $83 \%$ of 17000 children in the county need but do not receive ART. ${ }^{8}$ Indeed, ART's reach among HIV-positive clients in the county is significantly below the national a verages of $81 \%$ for adults and $38 \%$ for children. ${ }^{8}$ Furthermore, the Ministry of Health $(\mathrm{MOH})$ has identified several gaps in ART coverage: weak HIV testing and linkage to care and treatment, a high number of people who need ART, and children's access to ART lagging behind that of adults. ${ }^{9}$

HIV/AIDS care and treatment facilities often function in silos in Kenya, with minimal to no coordination with other facilities that offer complementary services. Lack of service documentation and patient follow-up contribute to poor interfacility referrals. This exposes clients to delayed, irrelevant, duplicate, or unnecessary care and services, which increase costs and result in poor health outcomes, including mortality. ${ }^{10}$

Effective testing, linkage, and continuity of care in Kenya will require robust coordination among facilities. Facilities within a community, removed extra space therefore, need to function as a network-that is, to be connected with each other in a variety of ways. In a network of organizations, the ties can be reflected in exchanges of information, resources, and clients. The Kenyan $\mathrm{MOH}$ recognizes the role of organizational networking and referrals in reducing costs and increasing access to and equity among essential health care services, such as HIV/AIDS treatment. The overall goal of its recently launched Kenya Health Sector Referral Strategy, 2014-2018 and companion implementation guidelines is to achieve the 90-90-90 targets through improved client treatment and access to care. ${ }^{1,7,9,11}$ The strategy's objectives are to improve health care providers' capacity to identify referral cases, develop protocols to improve the efficiency and effectiveness of the referral system, and promote and facilitate information and communication technology to manage referrals, improve care, enhance referral system capacity, provide communication and related equipment, and promote research and innovation for referrals. ${ }^{9}$ The strategy sets out 4 classes of referrals: clients, clinical expertise sent to the client, clinical specimens of the client, and client parameters or information. ${ }^{9}$

To contribute to the achievement of the national initiatives in HIV/AIDS care toward the 90-90-90 target, our study sought to reveal care linkages, or their absence, among organizations providing services to HIV-positive clients in Homa Bay County. The specific objectives were to (1) define referral network pathways in the HIV/AIDS services referral systems of Homa Bay, (2) quantify client movement among facilities within the HIV/AIDS services referral networks, (3) determine the quality of relationships within the HIV/AIDS services referral networks, and (4) establish determinants of client flow within the HIV/AIDS services referral networks. We had a particular interest in referrals between HIV testing and ART provision to support the UNAIDS goal of $90 \%$ of all people diagnosed with HIV infection receiving ART; and referrals for all services, including social services, as they can reduce personal challenges and thereby facilitate ART adherence and viral suppression, the third of the UNAIDS 90-90-90 goals.

\section{Methods}

\section{Study location}

For effective control of HIV/AIDS, the Kenyan $\mathrm{MOH}$ focuses resources on populations among whom prevalence is highest. ${ }^{7}$ Homa Bay County was selected for this study because it has the highest HIV prevalence in the country. ${ }^{8}$ Despite this burden, the county ranks 25 th and 21st, respectively, in adult and child ART coverage out of 47 counties nationwide, suggesting an urgent need for interventions that can link those who test HIV-positive to care. Our study considered health facilities and organizations providing HIV/AIDS care in Homa Bay County between June 2014 and September 2015.

The county lies along the south shore of Lake Victoria's Winam Gulf, approximately $420 \mathrm{~km}$ west of Nairobi. At the time of the study, it had a population of approximately 1 million (963 794) living in a geographical area of $3154.7 \mathrm{~km}^{2} .{ }^{12}$ About half $(48 \%)$ of the population is younger than 15 years old. And approximately half $(48 \%)$ lives below the poverty line, 
defined by the World Bank as earning less than US \$2 per day. ${ }^{13,14}$ Composing $85 \%$ of Kenya's Lake Victoria coastline, the county is Kenya's leading supplier of freshwater fish.

Administratively, Homa Bay has 8 subcounties: Homa Bay Township, Kabondo, Kasipul, Mbita, Ndhiwa, Rachuonyo North, Rangwe, and Suba. ${ }^{15}$ It has 226 private and public health facilities, with the county referral hospital located in the Homa Bay Township Subcounty. ${ }^{15}$ The Kenya Health Sector Referral Strategy, 2014-2018 envisions that clients should be referred from the community health unit to the dispensaries and health centers upwards through to the national referral facilities.

\section{Study design}

To determine the HIV/AIDS referrals occurring in Homa Bay County, we conducted an organizational network analysis consisting of 3 steps: (1) identify all organizations providing an HIV/AIDS service; (2) collect information on the organizations, including the services they provide; and (3) ask each one about its connections with other organizations in the county (eg, client referrals).

Network analyses are based on all of the relevant network participants, not a sample of them. The number of actors included is usually determined by the resources available for data collection. In our case, we aimed to include about 50 organizations. Thus, within the county, we focused on 2 contiguous subcounties: Homa Bay Township and Rangwe, with 2014 population estimates of 108148 and 113 961, respectively. ${ }^{16}$ The county health management team was consulted to review the choice of these 2 counties, to elicit input, and to secure local buy-in, which could facilitate coordination of the study, cooperation, and adoption and use of the study findings to improve practice.

The subcounties were selected on the basis of their high rankings in population size, number of health facilities, capacity of testing and treatment services, latest percentage of HIV-positive tests, and completeness of reported data.

\section{Organizations}

The Kenyan health system is categorized into 6 levels: level 1 is community health units; levels 2 and 3 include health centers and dispensaries; levels 4 and 5 include county and subcounty hospitals; and level 6 is national referral centers. The highest-level facility in the study area was the level 5 Homa Bay County Hospital, located in the Homa Bay Township Subcounty.

Facilities and organizations included in the study provided services in the HIV/AIDS care continuum
(HIV pre- and posttest counseling, testing, ART for adults and children, and prevention of mother-tochild transmission [PMTCT]) and operated within the boundaries of Homa Bay Township and Rangwe subcounties. They included private and public facilities. An initial list of 41 relevant facilities was obtained from the county master facilities list. Each was then asked to identify all relevant facilities it knew of in its catchment area. This process revealed an additional 15 facilities, for a study total of 56: 30 in Homa Bay Township and 26 in Rangwe.

\section{Data collection}

Each of the 56 facilities was represented by an appointed facility staff member with administrative and operational knowledge of the facility. They were interviewed in person about the characteristics of the organization and its interactions with other organizations. They were given permission to seek information from other staff members if needed.

The survey instrument included structured closedand open-ended questions. The closed-ended questions had preprogrammed response options or short answers, whereas responses for open-ended questions were summarized to capture the key points, not verbatim statements. Questions about the organizational attributes included the number and type of health care workers within the facility, the types of services offered, and the global positioning system coordinates. Questions about the connections with other organizations included the number and type of in and out referrals the previous 30 days with each of the other organizations and the quality of the interactions with the other facilities.

A trained interviewer administered the questionnaire, reading the questions and entering the responses using a mobile electronic tablet. The data were thus available for analysis the same day they were collected. Data collectors kept registers of contact information; scheduled, rescheduled, and completed interviews; and the facility name, name of interviewee, and date and time of interview.

\section{Data analysis}

The organizational characteristics were summarized as counts and proportions using Microsoft Excel and Stata $14 .{ }^{17}$ To map the organization locations, we used ArcGIS and QGIS (an open-source geographic information system software package). ${ }^{18}$

To describe and analyze the connections among organizations, we used UCINET6 software. ${ }^{19}$ We assumed a connection between 2 organizations existed if either of them reported at least one of the connections 
under consideration. UCINET analyzes each connection between every possible dyad of organizations in the network. In the case of our study, the connections analyzed were client referrals, shared resources (time, office s pace, $\mathrm{w}$ ritten $\mathrm{m}$ aterials, $\mathrm{p}$ amphlets, posters, supplies, drugs, laboratory, equipment, and staff), shared information (reports and formal and informal, communications), shared funds, and joint programs.

One of the statistics used to summarize the connections throughout the network, density, is the number of connections (eg, referrals) among organizations as a proportion of the total number of possible connections. Possible values range between 0 and 1. UCINET visualizes the connections in sociograms. We visually inspected these for the identification of $\mathrm{c}$ liques: $\mathrm{a}$ set of organizations that connect closely with one another and more distantly, if at all, with others.

We studied the effect of relationship quality between organizations on various outcomes using regression analyses; linear regression for continuous outcomes, such as the number of male and female clients; logistic regression for binary outcomes, such as having a written agreement with another organization (ie, yes or no); and ordered logistic regression for outcomes with several possible levels (eg, poor, fair, good, and excellent).

Organizational network analysis includes all of the relevant organizations. Since there is no sampling, test statistics for random error of estimates (eg, measures of association) do not apply. Thus, we report measures of association without test statistics.

This study was approved by ethics review committees and institutional review boards at the University of North Carolina at Chapel Hill, North Carolina (UNC Institutional Review Board Study \#142265 ) and the Kenyatta National Hospital/University of Nairobi's Ethics Review Committee, approval number KNH-ERC/A/267.

\section{Results}

Interviews were conducted with all 56 of the organizations identified. I n 10 i nstances, h owever, the intended respondent was unavailable and another staff member answered the questions. It cannot be known whether and how this affected the accuracy of responses. Respondents for the 56 organizations reported ties with 35 additional organizations that were not eligible for this particular network analysis because they did not provide HIV testing or ART services. The 35 organizations provided social services including housing, home-based care (HBC), nutritional supplements, legal support, family planning counseling, among others. They were all private, faith-based, or community-based organizations.

\section{Organizational characteristics}

Of the 56 facilities delivering HIV/AIDS services in the 2 subcounties, the government operated nearly two-thirds $(35$, or $62.5 \%$, consisting of 25 dispensaries, 7 health centers, 2 subcounty hospitals, and 1 referral hospital) (Table 1). The remainder were roughly equally divided between private $(\mathrm{n}=10)$ and civil society $(\mathrm{n}=11)$ providers. Nearly half of all facilities and organizations in the study were dispensaries, which offer primary health services, basic outpatient care, minor surgical and laboratory services, and maternity care and form the interface between the community and higher-level facilities.

Each subcounty had a hospital, although Homa Bay Township had, in addition, the county referral hospital. They had a similar number of health centers, but Rangwe had nearly twice as many dispensaries. Homa Bay Township had 3 times as many nonpublic facilities as Rangwe ( $\mathrm{n}=16$ and $\mathrm{n}=5$, respectively).

Nurses were the most common type of staff at facilities, followed by community-based staff (community health extension workers, community health workers, or volunteers) (Table 2). The number and types of personnel were similar in the subcounties, with the exception of medical doctors, who were twice as numerous in Homa Bay Township because of the referral hospital.

HIV/AIDS education, pretest counseling, and diagnostic testing were the most common services offered by 55 facilities. Legal and housing services were offered by only 7 facilities. Seventeen facilities screened

\begin{tabular}{|c|c|c|c|}
\hline $\begin{array}{l}\text { Type of Health Facilit } \\
\text { Kenya }\end{array}$ & Subcoun & Loma B & unty, \\
\hline & Sub & & \\
\hline Facility Type & $\begin{array}{l}\text { Homa Bay } \\
\text { Township }\end{array}$ & Rangwe & Total \\
\hline County referral hospital & 1 & 0 & 1 \\
\hline Subcounty hospital & 1 & 1 & 2 \\
\hline Faith-based hospital $^{\mathrm{a}}$ & 0 & 1 & 1 \\
\hline Health center & 3 & 4 & 7 \\
\hline Dispensary & 9 & 16 & 25 \\
\hline $\begin{array}{c}\text { Nongovernmental } \\
\text { organization }\end{array}$ & 6 & 1 & 7 \\
\hline $\begin{array}{c}\text { Community-based } \\
\text { organization }\end{array}$ & 1 & 0 & 1 \\
\hline Faith-based clinic ${ }^{a}$ & 2 & 0 & 2 \\
\hline Private health clinic & 7 & 3 & 10 \\
\hline Total & 30 & 26 & 56 \\
\hline
\end{tabular}

${ }^{a}$ Faith-based organizations are not counted among nongovernmental organizations or community-based organizations; they are a separate category that is not doublecounted elsewhere. 


\begin{tabular}{|c|c|c|c|}
\hline $\begin{array}{l}\text { Facility Personnel Types } \\
\text { County, Kenya }\end{array}$ & Subcounty & Homa & \\
\hline & Subc & & \\
\hline Staff Type & $\begin{array}{l}\text { Homa Bay } \\
\text { Township }\end{array}$ & Rangwe & Total \\
\hline Surgeon & 0 & 1 & 1 \\
\hline Medical doctor & 6 & 3 & 9 \\
\hline Clinical officer & 12 & 11 & 23 \\
\hline Nurse & 22 & 24 & 46 \\
\hline Laboratory technician & 13 & 12 & 25 \\
\hline Pharmacy technician & 6 & 5 & 11 \\
\hline Nutritionist & 2 & 1 & 3 \\
\hline Peer educator & 20 & 19 & 39 \\
\hline Voluntary testing counselor & 23 & 21 & 44 \\
\hline $\begin{array}{l}\text { Community health extension } \\
\text { worker }\end{array}$ & 16 & 12 & 28 \\
\hline Community health worker & 18 & 18 & 36 \\
\hline Paid volunteer & 6 & 8 & 14 \\
\hline Unpaid volunteer & 6 & 6 & 12 \\
\hline Linkage officer & 5 & 3 & 8 \\
\hline Health information officer & 4 & 5 & 9 \\
\hline Other staffa & 21 & 16 & 37 \\
\hline Total & 180 & 165 & 345 \\
\hline
\end{tabular}

${ }^{a}$ Types of other staff include security guard, grounds keeper, cleaner, dentist, maintenance officer, nurse aide, project coordinator, public health officer, optician, field officer, human resources officer, lay counselor, and social worker.

for gender-based violence and 16 provided care in this domain.

\section{Organizational connections}

Eighty percent of the interviewed facilities had at least one connection of any type with another facility in the previous 30 days (Figure 1). Most connections were for information exchanges and joint programing, defined as activities in a common work plan and related budget involving 2 or more facilities. ${ }^{20}$ The network density for connections of any type was 0.103 , with a median of 1 tie per facility. The organizations with the most connections-in network terminology, the most central organizations-were Ndiru Health Centre, Rangwe Subcounty Hospital, and Homa Bay County Referral Hospital.

Referral connections were relatively rare (Figure 2 ). The overall network density for client referrals was 0.021 , with a median of 0.5 ties per facility. Ndiru Health Centre, Rangwe Subcounty Hospital, and Homa Bay County Referral Hospital were the most central for referrals. There were 9 facilities that provided only HIV testing. Client referral for posttest

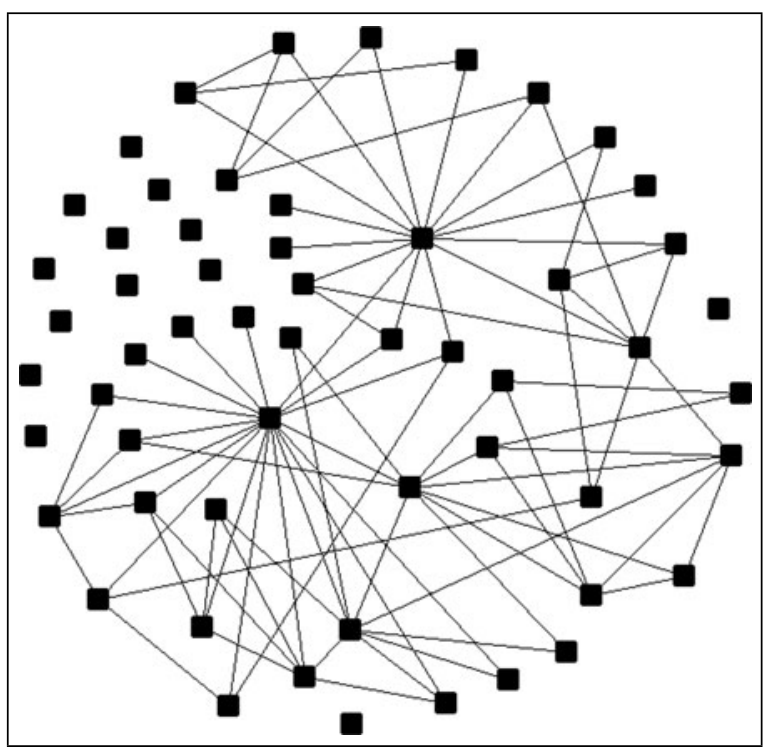

FIGURE 1 Sociogram of Ties of All Types Between HIV/AIDS-Related Organizations in Homa Bay County, Kenya ${ }^{a}$

a Network density $=0.103$.

HIV/AIDS services by these facilities was low or nonexistent. Private facilities offered fewer services, had fewer or no connections with other facilities, and referred fewer clients. Dispensaries, similarly, referred few clients.

All but one facility provided diagnostic testing. Of those, 12 did not dispense ART. Of the 12, 5 did not report referring clients for ART. Four of the 5 facilities were dispensaries. Three were in Homa Bay Township and 2 were in Rangwe; 3 were public facilities.

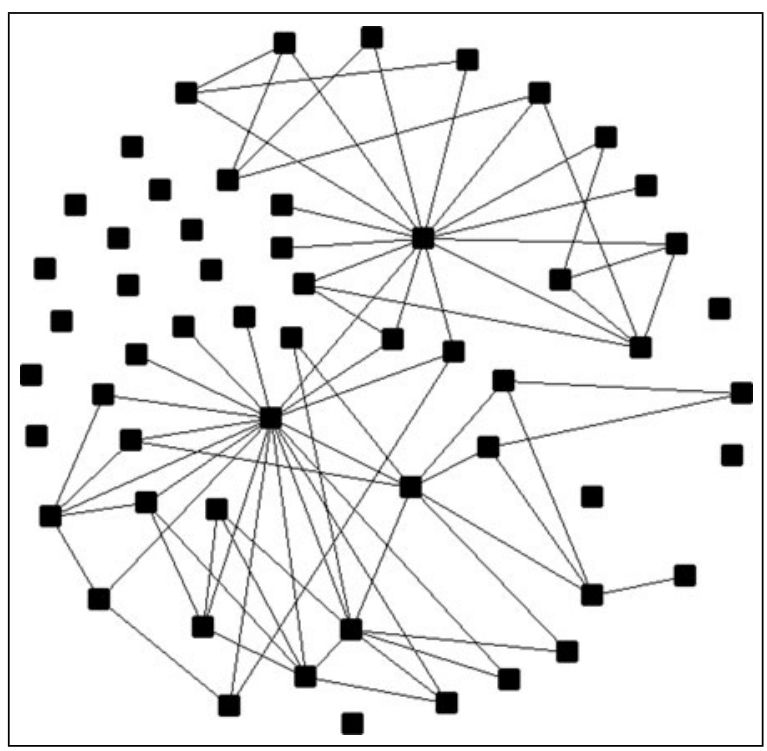

FIGURE 2 Sociogram of Client Referral Ties Between HIV/AIDS-Related Organizations in Homa Bay County, Kenya ${ }^{a}$

a Network density $=0.021$. 


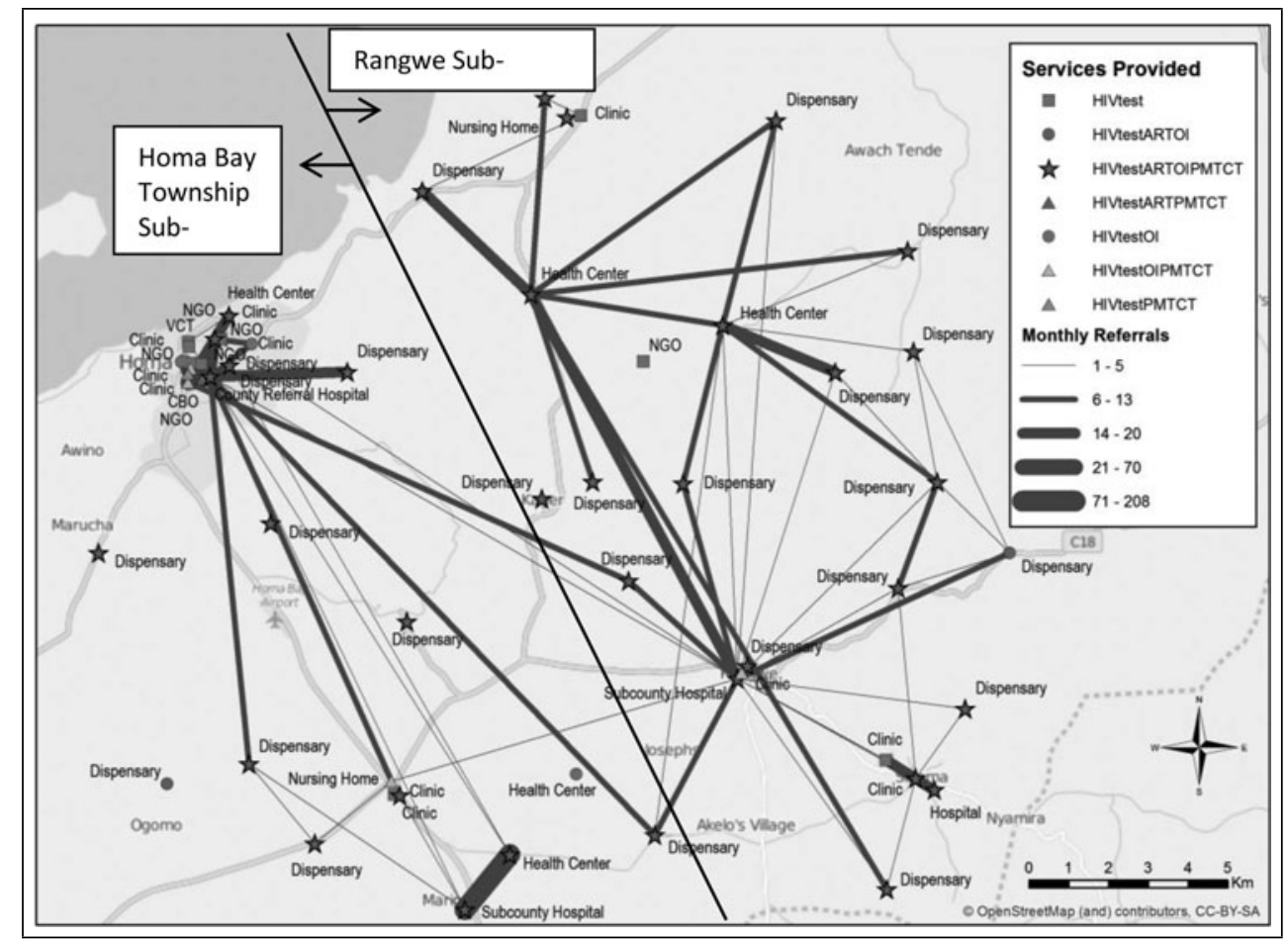

FIGURE 3 Geographical Representation of Client Referral Ties Between HIV/AIDS-Related Organizations in Homa Bay County, Kenya ${ }^{a}$ a The 2 subcounties are demarcated with an approximate line because Kenya adopted a county and subcounty system only recently, and geographical maps are not up to date.

Each had a catchment area of more than 15000 people. Their years of service ranged from 0 to 24 . Two facilities that did provide ART also referred clients for ART elsewhere.

Two clusters or organizational cliques are evident, with only 2 connections between the 2 cliques. To better understand these cliques, we overlaid a referral network on a map of the study area (Figure 3 ).

The map reveals that the cliques represent the 2 subcounties. Homa Bay County Referral Hospital was the point of centrality for Homa Bay Township, and Rangwe Subcounty Hospital was the central point for Rangwe.

The network analysis also revealed gaps in referrals for other HIV/AIDS-related services (Table 3). For example, Dispensary 5 did not provide the following services or refer its clients for them: ART, preventive therapy for opportunistic infections, treatment of tuberculosis (TB), and provision of prophylaxis for PMTCT and HBC for people living with HIV.

\section{TABLE 3}

\section{Example of Actual and Potential Referrals ${ }^{\mathrm{a}}$}

\begin{tabular}{|c|c|c|c|c|c|c|c|c|}
\hline Organization Name & $\begin{array}{c}\text { HIV } \\
\text { Diagnostic } \\
\text { Testing }\end{array}$ & $\begin{array}{c}\text { Dispense } \\
\text { ART }\end{array}$ & $\begin{array}{l}\text { Preventive } \\
\text { Therapy for } \\
\text { Opportunistic } \\
\text { Infections }\end{array}$ & $\begin{array}{l}\text { Treatment } \\
\text { of TB }\end{array}$ & $\begin{array}{c}\text { Treatment } \\
\text { of STls }\end{array}$ & $\begin{array}{l}\text { Provision of } \\
\text { Prophylaxis } \\
\text { for PMTCT }\end{array}$ & $\begin{array}{c}\text { Pediatric } \\
\text { HIV/AIDS } \\
\text { Care }\end{array}$ & $\begin{array}{l}\text { HBC for } \\
\text { PLHIV }\end{array}$ \\
\hline Hospital 1 & - & - & - & - & - & - & - & - \\
\hline Dispensary 1 & - & - & - & - & - & - & - & $\|$ \\
\hline Dispensary 2 & - & - & $\|$ & घ & घ & $\|$ & $\|$ & $\|$ \\
\hline Dispensary 3 & - & - & - & - & - & - & - & - \\
\hline Dispensary 4 & • & $\|$ & 口 & $\|$ & $\|$ & $\|$ & 口 & $\|$ \\
\hline Dispensary 5 & - & $\|$ & $\|$ & $\|$ & - & $\|$ & $\|$ & $\|$ \\
\hline
\end{tabular}

Abbreviations: ART, antiretroviral therapy; HBC, home-based care; PLHIV, people living with HIV; PMTCT, prevention of mother-to-child transmission; STI, sexually transmitted infection; TB, tuberculosis.

${ }^{a}$, service provided; $\mathbf{\square}$, service referred, but not provided; $\|$, service gap. 
Similarly, Dispensary 4 provided only HIV testing services. While it did make referrals for preventive therapy for opportunistic infections and pediatric HIV/AIDS care, it did not make referrals for ART, treatment of TB, treatment of sexually transmitted infections, prophylaxis for PMTCT, and HBC for people living with HIV.

The sociograms in Figures 1 and 2 show that several facilities were not connected in any way with any other facilities. These were principally nongovernment clinics (private, faith-based, or communitybased) in Homa Bay Township Subcounty.

\section{Factors affecting ties}

Forty percent of the facilities reported having a written agreement with other facilities, and nearly $70 \%$ had designated network facilitators committed to maintaining linkages with other facilities. There were 97 linkages representing joint programs in the network. Of these, approximately $30 \%$ reported a poor or fair relationship with the other; approximately $70 \%$ reported a relationship quality of good or excellent.

Having a designated network facilitator and having a written agreement between 2 facilities, each independently more than doubled the likelihood that a patient would be referred to the other organization $(159 \%$ and $138 \%$ increase, respectively). Having a joint program also independently increased the likelihood $(+87 \%)$, but relationship quality had little effect $(-7 \%)$. Having a network facilitator, in turn, increased the probability of having a joint program by $14 \%$. A larger annual operating budget was associated with resources for communication and transportation.

Respondents reported qualitatively that good relationships between organizations were facilitated by the availability of funds, information exchanges, good leadership, and high trust. Factors frequently reported as hindering effective partnerships were lack of information about services provided by others, competition for clients, poor coordination and sharing, lack of or unequal distribution of funding, and poor communication.

\section{Dissemination meeting}

The results of the study were presented to 25 to 30 Homa Bay stakeholders on August 6, 2015. The participants were representatives of the organizations studied: the country referral hospital, the 2 subcounty hospitals, and the county and subcounty offices. Unfortunately, a number of more senior decision makers were away at another meeting that was announced just a few days before this study's meeting.

The purposes of the meeting were to ask the local participants whether the data seemed to accurately reflect the situation in Homa Bay, to seek their insights for interpretation of the findings, and to discuss actions they would like to take in light of the findings. The study rationale, methods, and findings were presented to the group. Everyone present then discussed the findings. The participants validated the findings and expressed a desire for ongoing forums for networking to address challenges of mistrust among organizations, especially between private and public facilities. To facilitate this, they requested a directory of facilities with contact details, a county plan to enhance networking among facilities, and procedures for confirming referral completion. Since completion of the study, the researchers provided the participants with a directory and they are seeking additional resources to facilitate network strengthening.

\section{Discussion}

Homa Bay County has a sizable number of HIV/ AIDS-related service providers, but it still has the highest county prevalence of HIV/AIDS in Kenya. One interpretation of this apparent inconsistency is that most of those with HIV infection are being kept alive by ART, thereby keeping the prevalence high. This is one potential outcome of the 90-90-90 goal. However, the county's low ranking in ART coverage ( 25 th out of 47 counties) indicates that the high prevalence more likely results from high transmission, unabetted by treatment (and thus reduced infectiousness) of those infected with the virus. This network analysis focused on organizations either testing for HIV or providing ART. Another 35 organizations providing not these but other services needed by people infected with HIV were mentioned by those in our network. Those services, such as housing and counseling, may help those on ART to stay consistently on treatment and thus achieve viral suppression.

It appears from this network analysis that, before health officials move to provide more HIV/AIDS care services in Homa Bay, they should ensure that the services already provided are used to their fullest potential through an effective referral system. Inevitably, there is room for improving the services of each organization. But given HIV's complexity and the number of cases in Homa Bay County, the organizations will have to work together to achieve the synergies needed. Patient referral is an important example of the type of coordination required. 
The network analysis revealed much room for improvement in service coordination. The network density of 0.021 and the median of only one linkage of any type per facility can be considered quite low. It shows that facilities in the county rarely referred clients, exchanged information, shared resources, or implemented joint programs with one another. In particular, there is a need to improve referrals from facilities that test but do not treat to facilities that provide HIV/AIDS treatment.

Our study found that lack of information on services provided by others, lack of funding, lack of staff committed to maintain relationships with other facilities, and the absence of written agreements contributed to a low number of linkages. Conversely, facilities with committed network facilitators were more likely to have joint programs and significantly b etter $r$ elationships. A n e ffective network facilitator can share information on services, help write agreements, and generally build trust between organizations.

Together, these findings s uggest that having a designated network facilitator can improve the quality of organizational relationships and increase the number of clients referred. A network facilitator is also likely to initiate new relationships with facilities while maintaining existing ones, thus increasing network linkages.

Facilities in the same subcounty referred to one another more frequently than across subcounties, suggesting that proximity also facilitates connections. Strengthening connections with close-by neighbors is a reasonable way to enhance referrals, as long as the services needed are available in the subcounty. Of course, accessing services that are only in another subcounty will require the building of longer-distance relationships.

Some solutions for improving linkages may require policy-level interventions; for example, funding for network facilitators in public facilities. Other solutions may be low-cost and network-oriented solutions; for example, creating service directories and distributing them to all facilities and organizations in the network. In addition, creating a trusting environment and developing good rapport among facilities may be a low-cost intervention that can improve the quality of relationships. In Addis Ababa, Ethiopia, a series of 3 meetings among organization representatives, each spaced 2 months apart, increased the network referral density by $50 \%$, while in a control network, the density decreased. Moreover, client satisfaction with services increased in the improved network but not in the network that showed no improvement. ${ }^{21}$ Other potential solutions include facility-level interventions, such as developing procedures for

\section{Implications for Policy \& Practice}

On the basis of this study, we recommend that providers in Homa Bay County:

1. Share information with each other on services they provide.

2. Develop, maintain, and sustain a common client referral records system to be used by all facilities to eliminate discrepancies, facilitate client monitoring, and reduce the waste of resources used in HIV/AIDS care.

3. Find sustainable ways to designate network facilitators to initiate and maintain relationships with others in the network.

4. Initiate and maintain regular network strengthening and monitoring meetings where organizations can learn about one another, develop agreements, and grow in their trust of one another.

5. Use existing tools to identify and strengthen areas of the referral system that need improvement. Examples are MEASURE Evaluation's M\&E Capacity Assessment Tool and the Referrals System Capacity Assessment Tool.

6. Develop a system to trace and follow up with clients to help facilities and organizations manage client referrals more effectively.

With low-cost steps such as these, the county can improve care for people with HIV infection not necessarily by adding services but by getting more out of the services already provided. In this way, fewer people with HIV infection will be lost between HIV/AIDS diagnosis and HIV/AIDS treatment, and more will achieve HIV viral suppression by staying on ART.

accurate and sustained recording and follow-up for clients sent and received.

\section{References}

1. Joint United Nations Programme on HIVIAIDS. 90-90-90: An Ambitious Treatment Target to Help End the AIDS Epidemic. Geneva, Switzerland: UNAIDS; 2014.

2. International Association of Providers of AIDS Care. IAPAC guidelines on optimizing HIV care continuum recommend "Test and Start" irrespective of CD4 count. http://iapac.org/uploads/ IAPAC-PressRelease-2015-Guidelines-093015.pdf. Published September 30, 2015. Accessed May 21, 2018.

3. US Centers for Diseases Control and Prevention and Kenya Ministry of Health. The cost of comprehensive HIV treatment in Kenya. Report of a cost study of HIV treatment programs in Kenya. http://nacc.or.ke/wp-content/uploads/2016/03/Report-ARTCosting-Project-Kenya1.pdf. Published 2013. Accessed May 21, 2018.

4. United States Global Health Initiative. Principles: integration. https://usaidlearninglab.org/sub-group/integration/group-resource/ 
ghi-integration-framework. Published 2014. Accessed May 21, 2018.

5. Berwick D. Launching accountable care organizations-the proposed rule for the Medicare Shared Savings Program. N Engl J Med. 2011:364:e32

6. Thomas J, Reynolds H, Bevc C, Tsegaye A. Integration opportunities for HIV and family planning services in Addis Ababa, Ethiopia: an organizational network analysis. BMC Health Serv Res. 2014;14:22.

7. National AIDS Control Council. Kenya HIV Prevention Revolution Roadmap. Nairobi, Kenya: Kenya National AIDS Control Council; 2014.

8. National AIDS Control Council. HIV and AIDS Profile-Homa Bay County. Nairobi, Kenya: Kenya National AIDS Control Council; 2012.

9. Ministry of Health. Kenya Health Sector Referral Strategy, 20142018. Nairobi, Kenya: Kenya Ministry of Health, 2013.

10. Ministries of Medical Services, Public Health and Sanitation. Kenya National eHealth Strategy 2011-2017. Nairobi, Kenya: Government of Kenya; 2011.

11. National AIDS Control Council. Kenya AIDS Strategic Framework. Nairobi, Kenya: Kenya National AIDS Control Council; 2014.

12. Kenya National Bureau of Statistics. The 2009 Kenya Population and Housing Census. Nairobi, Kenya: Kenya National Bureau of Statistics; 2010.
13. The World Bank. Poverty overview. http://www.worldbank.org/en/ topic/poverty/overview. Published 2014. Accessed May 21, 2018.

14. Kenya National Bureau of Statistics. Exploring Kenya InequalitiesHoma Bay County. Nairobi, Kenya: Kenya National Bureau of Statistics; 2014.

15. Kenya Information Guide. Overview of Homa Bay County. http:// www.kenya-information-guide.com/homa-bay-county.html. Published 2014. Accessed May 21, 2018.

16. Kenya OpenData. County data sheet-Homa Bay. https://opendata. go.ke/facet/counties/Homa \pm Bay. Published 2014. Accessed August 1, 2016.

17. StataCorp. Stata [computer software]. College Station, TX: StataCorp LLC; 2013. http://www.stata.com. Accessed May 21, 2018.

18. Environmental Systems Research Institute(ESRI). ArcGIS [Computer software]. Redlands, CA: ESRI; 2011. http://www.esri.com/ software/arcgis. Accessed May 21, 2018.

19. Borgatti SP, Everett MG, Freeman LC. UCINet for Windows: Software for Social Network Analysis. Cambridge, MA: Analytic Technologies; 2002

20. UNDP. Financial resources. https://info.undp.org/global/popp/frm/ pages/joint-programming.aspx. Accessed July 26, 2016

21. Thomas JC, Reynolds H, Alterescu X, Bevc C, Tsegaye A. Improving referrals and integrating family planning and HIV services through organizational network strengthening. Health Policy Plann. 2016:31(3):302-308. 